\title{
Beyond the connoisseurship approach: creating a chronology in Hokusai prints using non-invasive techniques and multivariate data analysis
}

Marc Vermeulen ${ }^{1,6^{*}} \mathbb{D}$, Lucia Burgio ${ }^{2}$, Nathalie Vandeperre ${ }^{3}$, Elyse Driscoll ${ }^{4}$, Madeleine Viljoen ${ }^{5}$, Janie Woo ${ }^{1}$ and Marco Leona'

\begin{abstract}
This study combines scientific and connoisseurship approaches to establish a production chronology of 141 woodblock prints from Katsushika Hokusai's series Thirty-Six Views of Mount Fuji belonging to different cultural institutions in Europe and the United States. In order to create this chronology, the reflectance spectroscopy (FORS) signature of the indigo/Prussian blue mixture of the key-block printed outlines was measured and compared using multivariate data analysis. This approach yielded 9 clusters of prints, each one presenting slightly different FORS features, and therefore, different Prussian blue/indigo mixtures. The connoisseurship approach was then applied to impressions of the same print found across the 9 clusters. This allowed for arrangement of the clustered prints according to their production time, resulting in a comprehensive timeline for the 141 prints examined. To date, this work represents the only systematic study of such a large corpus of Japanese/Hokusai woodblock prints integrating chemical analysis and statistical treatment of data with careful visual examination of the prints. The result is a novel approach to creating a chronology for these objects. Our study easily differentiated between early nineteenth and early twentieth century prints as well as between various printing batches/clusters. Creating a chronology of such an important print series is also crucial to understand the evolution of artist and printing studio practices in late nineteenth-century Japan, a period of great economic and cultural changes.
\end{abstract}

Keywords: Hokusai, Japanese woodblock prints, FORS, Chemometrics, Chronology

\section{Introduction}

The commercial production of multi-block color prints in Japan during the Edo period was an involved process. The print publisher planned a new woodblock print as a commercial product and commissioned an artist to create a preparatory drawing. The publisher then sought permission from the censor, a governmental or military organization that would ban anything deemed

\footnotetext{
*Correspondence: marc.vermeulen@northwestern.edu

${ }^{6}$ Present Address: Northwestern University/Art Institute of Chicago Center for Scientific Studies in the Arts, Technological Institute, 2145 Sheridan Road, Evanston, IL 60208, USA

Full list of author information is available at the end of the article
}

as indecent, to publish the design, receiving a stamp of approval, before the drawing was given to a block carver. The carver adhered the preparatory drawing face down to a wood block and carefully carved the block to match the lines of the drawing. A test proof, or key print, was printed in sumi ink, a mixture of soot and animal glue. Copies of the key print were given to the artist who indicated the color areas on the image. The annotated key print sheets were returned to the block carver and a separate block of wood was carved to print each individual color. The blocks were then given to the printer. Using a brush, the printer combined the colorant with a small amount of water and rice starch paste and applied it to
Springer Open

(c) The Author(s) 2020. This article is licensed under a Creative Commons Attribution 4.0 International License, which permits use, sharing adaptation, distribution and reproduction in any medium or format, as long as you give appropriate credit to the original author(s) and the source, provide a link to the Creative Commons licence, and indicate if changes were made. The images or other third party material in this article are included in the article's Creative Commons licence, unless indicated otherwise in a credit line to the material. If material is not included in the article's Creative Commons licence and your intended use is not permitted by statutory regulation or exceeds the permitted use, you will need to obtain permission directly from the copyright holder. To view a copy of this licence, visit http://creativeco mmons.org/licenses/by/4.0/. The Creative Commons Public Domain Dedication waiver (http://creativecommons.org/publicdomain/ zero/1.0/) applies to the data made available in this article, unless otherwise stated in a credit line to the data. 
the raised surface of a dampened wood block. The printer placed the key-block printed sheet face down on a color block and rubbed the moistened, sized paper with a hard circular pad (baren tool) until the color was transferred to the sheet. An image was pulled from a succession of the blocks to produce the finished color print [1-3].

Ukiyo-e, which translates as "picture(s) of the floating world", is a genre of Japanese art that flourished from the seventeenth through the nineteenth centuries. Artists such as Moronobu, Masanobu, Utamaro or Sharaku were praised for their depictions of female beauties, actors, and erotica, while landscape depiction was mastered by artists such as Hokusai and Hiroshige. ThirtySix Views of Mount Fuji, by Hokusai, is perhaps one the most renowned landscape print series of all time and includes the acclaimed Under the Wave Off Kanagawa, also known as The Great Wave (Fig. 1, left). This print series, whose production began between 1830 and 1832, is also an ode to the newly-introduced Prussian blue pigment, the first modern synthetic pigment ever produced [4], most likely brought in Japan in the early part of the nineteenth century through trade with China or the Netherlands [5, 6]. Due to its vibrant color, Prussian blue led to what has been referred to as the "blue revolution" in Japanese woodblock prints [7]. Previously, indigo and dayflower blue, two natural colorants, had been the main source of blue used by Japanese artists [8]. However, both colorants were not fully satisfactory: the former has a dull hue at full density, and the latter is not stable when exposed to light and humidity. With the introduction of the imported pigment, blue became a prominent hue in artistic print production. Aizuri-e-or monochrome blue printed pictures-of which impressions from Hokusai's Thirty-Six Views of Mount Fuji are remarkable examples (Fig. 1), are a testimony to the interest of the public for this novel color. Blue was so important in Hokusai's production of the Thirty-Six Views of Mount Fuji series that even the key-block printed outlines of the original thirtysix designs were created using blue rather than the customary black sumi ink $[9,10]$.

All 36 designs from the series are provided in Additional file 1: Figs. S1-S36. Due to the popularity of the print series, 10 additional designs were created in the mid-1830s. Nonetheless, because these 10 additional views feature black outlines, they were considered out of the scope of this article and were therefore not included in this study.

The publisher, Nishimura Yohachi (Eijudō), advertised the series as being aizuri-e, clearly highlighting the genre as an established category, and a selling point ("Thirty-Six Views of Mt. Fuji, by Zen Hokusai Iitsu; single-sheet aizuri. One view to each sheet, to be published one after the other" [7]). However, despite the emphasis put by the publisher on the use of blue in the Thirty-Six Views of Mount Fuji, the blue outlines of the print series are not composed of Prussian blue alone. Previous studies of these prints using fiber optic reflectance spectroscopy (FORS) highlight the use of Prussian blue/indigo mixtures in the blue outlines [9-11]. As demonstrated in these studies $[9,12]$, FORS is well suited to differentiate Prussian blue from indigo as the two colorants show different reflection spectra. Indigo shows a maximum absorption around $660 \mathrm{~nm}$ and reflects most of the light in the 700-950 nm range, while Prussian blue absorbs most of the radiations in both the visible and near infrared ranges. When mixed, the contributions of both colorants is observed as follow: a maximum absorption at around $660 \mathrm{~nm}$ and an increased absorption in the $700-950 \mathrm{~nm}$ range compared to pure indigo, due to the absorption of the Prussian blue in this range $[9,12]$.

An in-depth multi-analytical study (FORS, Raman, $\mathrm{XRF}$, multispectral imaging, digital microscopy) of the four impressions of Under the Wave Off Kanagawa and the three impressions of Storm Below the Summit, all

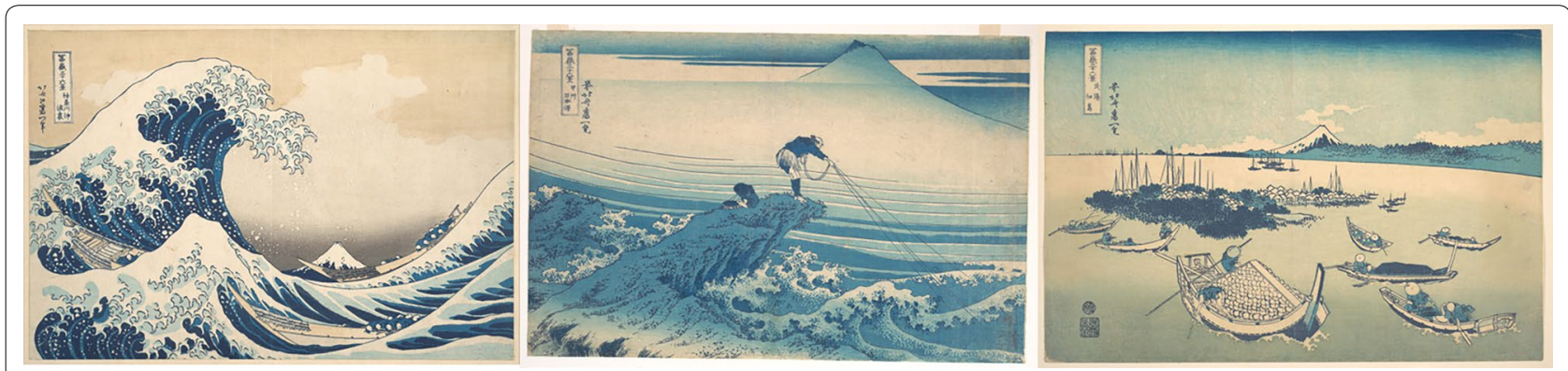

Fig. 1 Examples of three aizuri-e from the Thirty-Six Views of Mount Fuji by Katsushika Hokusai. (left) Under the Wave Off Kanagawa, Accession Number JP2569, $25.4 \times 38.1 \mathrm{~cm}$; (middle) Kajikazawa in Kai Province, Accession number JP2581, 25.4 × 38.4 cm; and (right) Tsukudajima in Musashi Province, Accession number JP2563, $25.4 \times 38.7$ cm. ca. 1830-32, The Metropolitan Museum of Art, The Howard Mansfield Collection, Purchase, Rogers Fund, 1936 
from the Metropolitan Museum of Art (the Met) collection, shows that the blue outlines are composed of Prussian blue/indigo mixtures. The mixtures used in the prints appear to vary, with the latest prints having a more intense reflectance response in the 700-950 nm range. This indicates that FORS may be useful in distinguishing various production times of the same print design.

A very popular print series such as the Thirty-Six Views of Mount Fuji was likely printed over an extended period of time and reprinted well beyond its original production cycle. Establishing a chronological printing order as well as dating the various prints has always been a difficult task, particularly when censor seals are not present on an impression. Between the late eighteenth century and the mid-nineteenth century, all woodblock prints were examined by official censors and marked with their seals. Variations in censor seals over time is well documented, making it possible to associate a date with a print to a varying degree of accuracy $[13,14]$. In the absence of seals, as is the case in all prints from the Thirty-Six Views of Mount Fuji, another method of establishing chronology is to resort to the connoisseurship approach. Connoisseurship of Japanese woodblock prints is an avenue of art historical inquiry that relies on close examination to assess differences in color intensity, design, line definition and condition among prints of the same design. This approach can provide valuable insight into a given print's origin, quality, and authenticity as it relates to its time of production. Wear and tear accumulating on the blocks after hundreds of impressions is particularly apparent in the outlines (printed with the key-block) and corresponds to widening of the printed lines, as well as small losses in the block due to the repetitive passage of the baren onto the thinly carved lines of the wood surface.

Approximately two hundred prints could be produced in a single day and a popular print could be reissued in as many as several thousand impressions. The first edition may have been printed with care and attention to detail but as the edition progressed and the audience broadened, the printer and publisher were less conscientious about the application of color. Costs could be reduced by using less skilled labor or by omitting some color blocks altogether and damaged or worn blocks could be recut [1].

The connoisseurship approach has previously been applied to Hokusai prints by Rogers Keyes and Peter Morse in a Catalogue Raisonné of the Single-Sheet Colour Woodblock Prints of Katsushika Hokusai (1760-1849) [15]. Nonetheless, this approach is time consuming (that study was realized over a period of 35 years, from 1972 to 2007) and only allows for comparison of impressions of the same design. No cross-connection can be made between two different designs from the same series.
More recently, scientific studies of prints by Hokusai looked at several impressions of a single design to understand the creation process and sequence of impressions $[9,10]$. Nonetheless, these studies focused on a limited number of impressions belonging to single designs and did not involve broad studies of large series.

Our previous work on four impressions of The Great Wave, three impressions of Storm Below the Summit (unpublished) and three impressions of Mishima Pass in Kai Province [9] bringing together scientific analysis and the connoisseurship approach proved crucial in determining the production chronology of the Met prints. In the current study we extend the application of this combined approach to the analysis of a much larger corpus of impressions from the Thirty-Six Views of Mount Fuji series, including prints from The Metropolitan Museum of Art (NY, USA), the Victoria and Albert Museum (London, UK), the Royal Museums of Art and History (Brussels, BE), the New York Public Library (NY, USA) and the Brooklyn Museum (NY, USA). In this study, it is hypothesized that all prints created at the same time in the same studio would feature similar paper composition (not studied here) and pigments/colorants. Therefore, each cluster corresponds to a batch of prints created simultaneously. Using FORS, we focused on the chemical composition of the blue outlines, a mixture of indigo and Prussian blue most likely characteristic of a specific production batch, to cluster the various prints from the five different collections into groups using multivariate analysis. The respective chronology of each group can subsequently be assessed using the connoisseurship approach, that is, by comparing the line quality of impressions of specific prints across the various clusters, to create a complete chronology of the production of prints from the Thirty-Six Views of Mount Fuji.

\section{Materials and methods}

\section{Woodblock prints}

Prints from different collections including the Metropolitan Museum of Art (Met, NY, USA), the Victoria and Albert Museum (V\&A, London, UK), the Royal Museums of Art and History (MRAH, Brussels, BE), the New York Public Library (NYPL, NY, USA) and the Brooklyn Museum (Brooklyn, NY, USA), were investigated non-invasively using FORS and Raman spectroscopy (the latter only applied to prints from the Met collection and the V\&A). In total, we examined 145 impressions of the Thirty-Six Views of Mount Fuji series by Katsushika Hokusai (1760-1849), of which 141 were used in the statistical model. 
All prints reported here feature the blue outlines that are characteristic of the original thirty-six designs and were allegedly printed over the period 18301832. All colors in each print were examined, but we chose to focus on the blue outlines as a chemical signature for the production timeframe. Impressions with black sumi outlines were not analyzed.

A full list of all analyzed prints and their details is given in Additional file 1: Table S1).

2. Fiber optic reflectance spectroscopy (FORS) FORS was performed in situ with an Ocean Optics QE65 Pro spectrometer (Dunedin, FL, USA) equipped with an Ocean Optics HL-2000 Tungsten halogen light source. The detector and light source were connected with a high $\mathrm{OH}$-fused silica fiber optic bundle consisting of eight $600 \mu \mathrm{m}$ fibers (used to transport the light from the source to the sample) arranged around a single $800 \mu \mathrm{m}$ fiber (to transport the signal from the sample to the detector). The distal end of the probe is partially fused to form a spherical lens that focuses both illumination and detection fibers to the same spot, with a working distance of approximately $1 \mathrm{~mm}$.

The spectral range of the detector is $200-1000 \mathrm{~nm}$, with an $0.8 \mathrm{~nm}$ resolution; nevertheless, due to poor light output on the extremes of the range, only the range between 400 and $900 \mathrm{~nm}$ was considered. Spectra were referenced against the SRS-99-010 Spectralon ${ }^{\circledR}$ diffuse white standard provided by Labsphere (North Sutton, NH, USA) to avoid fluctuation of spectrum intensity. Ten $10 \mathrm{~ms}$ integrations were collected and averaged to produce the mean spectra used in the study. Spectra were neither corrected nor normalized before being used for the statistical model.

The system was managed by the OceanView 1.6.7 software for Windows and data processed with the Unscrambler X 10.5 (CAMO Software, Oslo, Norway) and/or OriginLab 8.0.

3. Raman spectroscopy and surface enhanced Raman spectroscopy (SERS)

Micro-Raman spectroscopy spectra on the Metropolitan Museum impressions were acquired with a Bruker Senterra Raman spectrometer coupled with an LMPlanFL Olympus $50 \times$ long working distance microscope objective and a charge-coupled device (CCD) detector. A continuous wave diode laser, emitting light at $785 \mathrm{~nm}$, was used as the excitation source, and a 1200 rulings $/ \mathrm{mm}$ holographic grating provided a spectral resolution of $3-5 / \mathrm{cm}$. All Raman spectra were recorded with $1 \mathrm{~mW}$ output laser power at the sample. Acquisition time varied depending on the color investigated. For the blue and green areas, the acquisition time was of 4 min (four successive $60 \mathrm{~s}$ accumulations), while it was set to one minute (two successive $30 \mathrm{~s}$ accumulations) for all other colors (mostly yellow, yellow component of the green, orange and red). These parameters are well suited to avoid structural modifications to the Prussian blue while still allowing spectra with acceptable signal to noise ratio [16]. The blue colorants spectra were acquired in the $1515-2635 / \mathrm{cm}$ range permitting the visualization of the characteristic bands of both indigo and Prussian blue while all other colors were acquired in the $60-1500 / \mathrm{cm}$ range, suitable for most inorganic pigments.

The Raman analysis of several of the V\&A prints was performed using a Horiba XploRA spectrometer equipped with two diode lasers (532 and $638 \mathrm{~nm}$ ) and an Olympus microscope. Only the $50 \times$ objective was used. The power at the sample was always kept below $1 \mathrm{~mW}$. Total accumulation times varied between $20 \mathrm{~s}$ and $1 \mathrm{~min}$ and no spectral manipulations were used. The spectra obtained from the prints were compared to reference spectra collected in house and to those in published databases $[17,18]$.

SERS was used as supplementary technique when organic colorants were suspected. The silver colloid was prepared by microwave supported reduction of $\mathrm{Ag}_{2} \mathrm{SO}_{4}$ in the presence of glucose and sodium citrate [19]. The colloid was concentrated 5 times by centrifuging $1 \mathrm{~mL}$ of colloid and replacing $950 \mu \mathrm{L}$ of the supernatant liquid with $150 \mu \mathrm{L}$ of ultrapure water. Samples were obtained from the prints by removing fragments of single paper fibers $(\sim 100 \mu \mathrm{m}$ in length $)$ using a tungsten needle and/or tweezers. To minimize the damage to the prints, fibers already raised from the surface or partially detached were selected. Prior to the SERS analysis, the sample was exposed to HF vapor for $5 \mathrm{~min}$ at room temperature. After the treatment, a $2 \mu \mathrm{L}$ drop of colloid was delivered onto the sample, followed by $\sim 0.5 \mu \mathrm{L}$ of $0.1 \mathrm{M} \mathrm{KNO}_{3}$ solution to induce aggregation. SERS spectra were acquired using the same Bruker Senterra Raman instrument as previously described, exciting the sample at $488 \mathrm{~nm}$ (Spectra Physics Cyan) through a 20x long working distance objective. The laser power on the specimen was kept below $0.4 \mathrm{~mW}$. The laser beam was focused inside the silver nanoparticle drop. All the spectra were acquired for $30 \mathrm{~s}$, with a resolution of $3-5 / \mathrm{cm}$.

Spectra were acquired using OPUS 7.0 Raman software and processed with OriginLab 8.0. 
4. Multivariate data analysis

Reflectance spectra from areas of blue, green, yellow, brown, red and from the unprinted paper were measured in the 141 prints discussed above. The study resulted in a large dataset composed of $\sim 900$ spectra, 234 of which correspond to the blue outlines.

In order to help sorting the large spectroscopic dataset, multivariate analysis was employed. The software used for developing the model was the Unscrambler X 10.5 (CAMO Software, Oslo, Norway). All reflectance spectra obtained on the selected prints were included in the matrix. Additional information such as accession number, collection and color associated with the analyzed spots were added as text variables, allowing several variables to be visualized in PCA. The following spectral pre-treatments and combinations thereof were tested to assess their effect on the calibration performance. Scatter correction pre-treatments including mean, area and range normalization, standard normal variate, de-trending and multiplicative scatter correction were tested to minimize the nonlinear effect of light scatter due to particle size differences and paper substrate among samples. Different orders of derivative were also tested, mainly applying first and second derivatives using 5-point SavitzkyGolay smoothing. Due to the poor light output on the extremes of the range, indicated by the significant noise, the PCA on the dataset obtained on all the colors was performed using the 400-900 $\mathrm{nm}$ range of the FORS spectra. However, due to the strong contribution of the paper in the 400 to $600 \mathrm{~nm}$ range, only the 600 to $900 \mathrm{~nm}$ range was selected for the purpose of the statistical study on the blue outlines. This range includes all important features relative to indigo and Prussian blue such as the $660 \mathrm{~nm}$ maximum absorption for the indigo and the variable slope between 700 and $900 \mathrm{~nm}$. Ultimately, due to the excellent signal to noise in the selected range, no smoothing was applied to the dataset. However, a range normalization pretreatment was applied to the dataset prior to principal component analysis (PCA) and hierarchical cluster analysis (HCA). The software offers three normalization methods: mean, maximum, and range normalization. Range normalization was chosen in this case due to its limited impact on the data (equation available online in The Unscrambler Appendices: Method References, [20]). Each row is divided by its range, i.e. max value-min value [21] and allowed to minimize the minor influence of the paper substrate in the initial part of the range without drastically modifying the dataset. The impact of the range normalization on the clustering was tested using prints we knew should be grouped together, early prints with specific spec- tral signal or late-ninettenth/early-twentieth century prints. Both PCA and HCA approaches were used as methods of cluster analysis, seeking to build a hierarchy of clusters based on similarities and differences between the various FORS spectra. This can therefore be used to highlight the relationships between the various prints. For PCA, a non-linear iterative partial least squares (NIPALS) algorithm with a random (20 segments) cross validation method was used. For both cases, the total number of components were set to 7 with only 4 (for all colors dataset) and 3 (blue outlines dataset) optimal number of components suggested by the model. For HCA, the Ward's method using Squared Euclidean distance agglomerative or "bottomup" approach was used. This means that each observation starts in its own cluster, and pairs of clusters are merged as one moves up the hierarchy. The results from PCA are visualized in score plots while the HCA results are given in a dendrogram.

\section{Results and discussion}

Indigo and Prussian blue are the two constituents of the blue ink used for the key-block. One of the particularities of the mixture is that the two colorants do not present the same stability. Indigo is known for being less lightfast than Prussian blue [22-24]. Therefore, it is important to make sure that all prints analyzed do not present significant differences in light-induced degradation, leading to an alteration of indigo. Consequently, all prints presenting apparent signs of color discoloration (such as fading and yellowing) or degradation were removed from the statistical model. Orpiment, a yellow pigment commonly used in Japanese woodblock prints [8-10] is also well known for its light sensitivity leading to the formation of arsenic oxide $[25,26]$. Previous study showed that, prior to forming arsenic oxide, the orpiment crystals undergo structural modification leading to subtle but characteristic changes in the Raman signal [27]. This characteristic was also used to assess the light-induced damages to the prints. If significant light-induced damages were identified during the Raman study, the prints in which they were found were removed from the study. After careful observation, 141 prints from the five different collections were included in the statistical model.

In addition to the blue outlines, the paper support as well as any other colorants, including red, yellow, green, blue, orange were analyzed. This was important as, similarly to the ink composition of the outline, in which no major differences are expected within a single batch (but notable differences are expected between batches), no pigment variations are expected within similar prints realized at part of the same batch. It is however difficult to examine all colors for each of 141 prints separately. 
Therefore, PCA was applied to the FORS data set. This extensive data set includes all FORS spectra collected on the various colors in the full set of prints. The PCA plot for this full data set is given in Fig. 2. PCA is a data reduction technique which allows for an easier visualization and understanding of a complex dataset. This technique has been successfully used in the field of cultural heritage [28-31]. PCA plots are divided in four quadrants, which will express how the variables are correlated. Variables inversely correlated will be positioned on opposite sides of the plot origin. Furthermore, the distance to the origin also conveys information. The further away from the plot origin a variable lies, the stronger the impact that variable has on the model. The principal components (PCs) depend on the dataset and correspond to the new variables, which explain the most variations of the dataset [32]. Figure 2 obtained on the entire dataset clearly shows trends based on the colors. Yellow pigments, orange pigments, and the paper each create overlapping but clearly identifiable groupings in the lower right quadrant, indicating that little variation is observed throughout the entire print run. Loadings plots associated with PC-1 and PC-2 (Additional file 1: Fig. S37), show that these groupings share similarities in the 450-650 spectral range. Red pigments, while clustered mostly along the yellow/orange/paper quadrant, also present a smaller sub-grouping in the lower left quadrant. This shows that several types of pigments were most likely used. They were identified as iron oxide red, vermilion, and minium using Raman spectroscopy and FORS. Minium and vermilion, due to their sigmoid-shaped spectra with inflection point at 565 and $600 \mathrm{~nm}$, respectively, are most likely grouped together along with the yellows, oranges, and the paper, which are also characterized by similarly sigmoid-shaped reflectance curves. Greens, blues, and the outlines are the colors presenting the most extensive range, as suggested by their scattering throughout three quadrants of the PCA plot (upper right and left and lower left). Loadings plots (Additional file 1: Fig. S37) suggest a significant influence of the $700-740 \mathrm{~nm}$ range, most likely related to the indigo. Nonetheless, some of the blue found along the outlines could actually correspond to dark blue hues, in which both Prussian blue and indigo are found in admixture to create darker shades of blue, as previously demonstrated in a recent publication $[9,10]$. Blues and greens appear mostly scattered in the upper right quadrant, without clear sub-groupings. The outlines, even though scattered through the lower left quadrant, do seem to arrange themselves in smaller groups. To investigate the subgrouping of the outline data, PCA

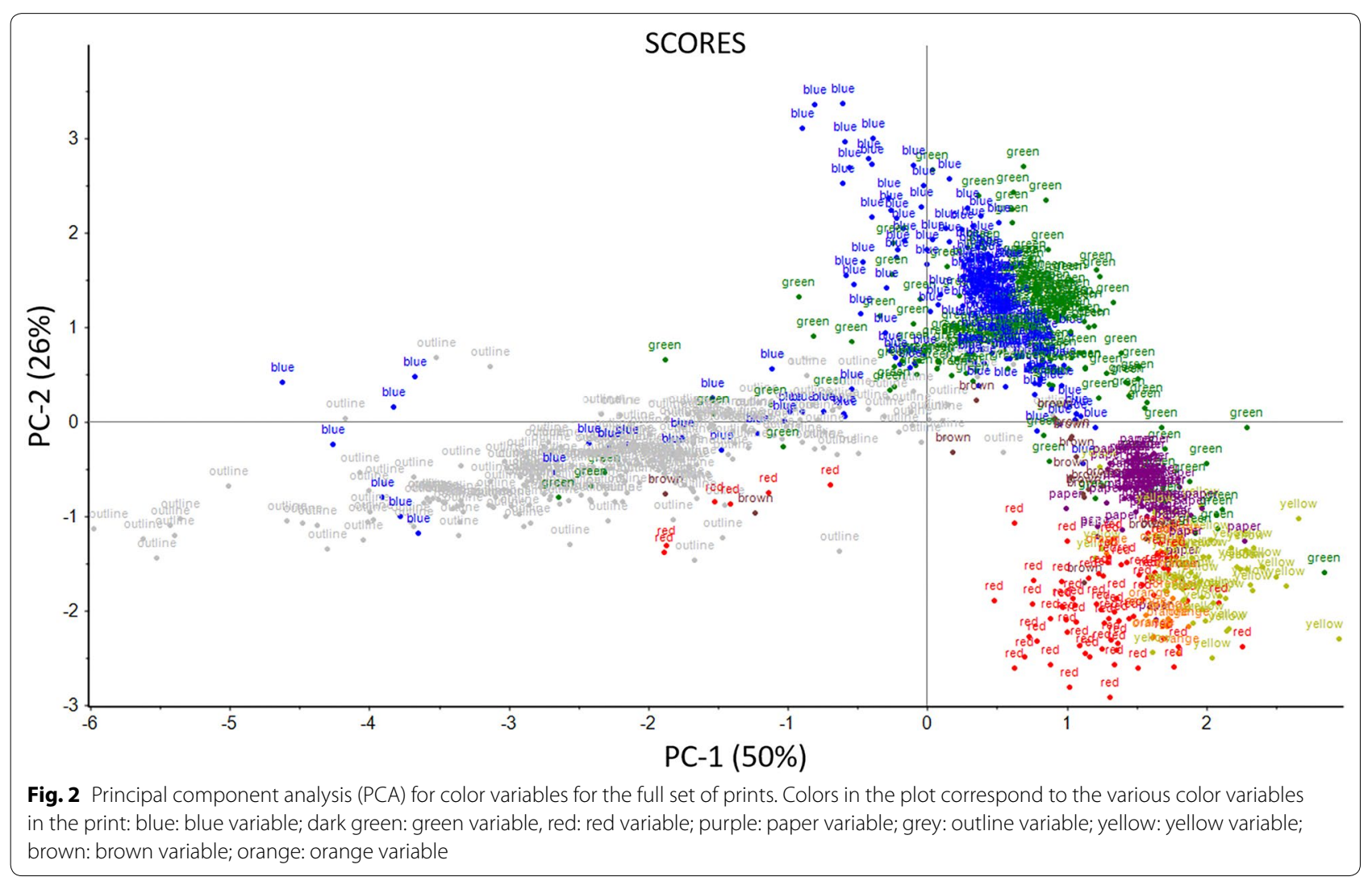


analysis was further applied on the outline dataset only, discarding all data from the other colored areas.

The PCA plot for the outlines-only data set is given in Fig. 3.

According to Fig. 3, three primary clusters can be identified: one composed of six impressions in the upper right quadrant, one with three impressions in the lower right quadrant and another one with most of the prints spreading over the four quadrants. The associated loading plots are given in Additional file 1: Fig. S38 and shows the great influence of the 720-900 range for the negative values of $\mathrm{PC}-1$. This range includes the inflection point associated with the indigo and the slope associated with both indigo and Prussian blue. It is important to note that PC1 represents $91 \%$ of the overall variance of the data set. This is easily explained by the relative similarity of the entire data set. Indeed, while the data set used for the PCA in Fig. 2 regrouped all pigments found in the prints, the data set used for Fig. 3 regroups only the data for the Prussian blue/indigo mixture. Therefore, most data here will present very similar features (max absorption at ca. $660 \mathrm{~nm}$, inflection point at ca. $720 \mathrm{~nm}$ and a slope in the 700$900 \mathrm{~nm}$ range). The main difference within the data set will be the degree of the slope in the 700-900 nm range due to the variation in indigo/Prussian blue mixtures.
For this reason, PCA may not be the method of choice to cluster the data obtained on the outlines. HCA using the bottom-up approach was then considered as a more suitable alternative. This approach starts each print in its own cluster and highlights cluster pairings based on their similarities. As a result, prints presenting the highest similarities in maximum absorbance, inflection point, and slope will be clustered together while larger dissimilarities such as the variations in slope will prevent different clusters to be merged. The resulting dendrogram is given in Fig. 4. This dendrogram clearly shows that the corpus of 141 prints divides into 9 different clusters. Two of these clusters (clusters 6 and 7) are the same as the two smaller clusters observed in the PCA (Fig. 3) while the main PCA cluster is divided into 7 sub-clusters. The cluster to which each print belongs is given in Additional file 1: Table S1.

Based on our hypothesis that the indigo/Prussian blue mixture used for the outlines is characteristic of each printing session, these 9 clusters represent 9 different production batches. Representative reflectance spectra for each cluster are given in Fig. 5. No major variations of unmixed pigments or colorants are expected within the clusters of prints produced at the same time in the same place outside of the specific individual mixture of

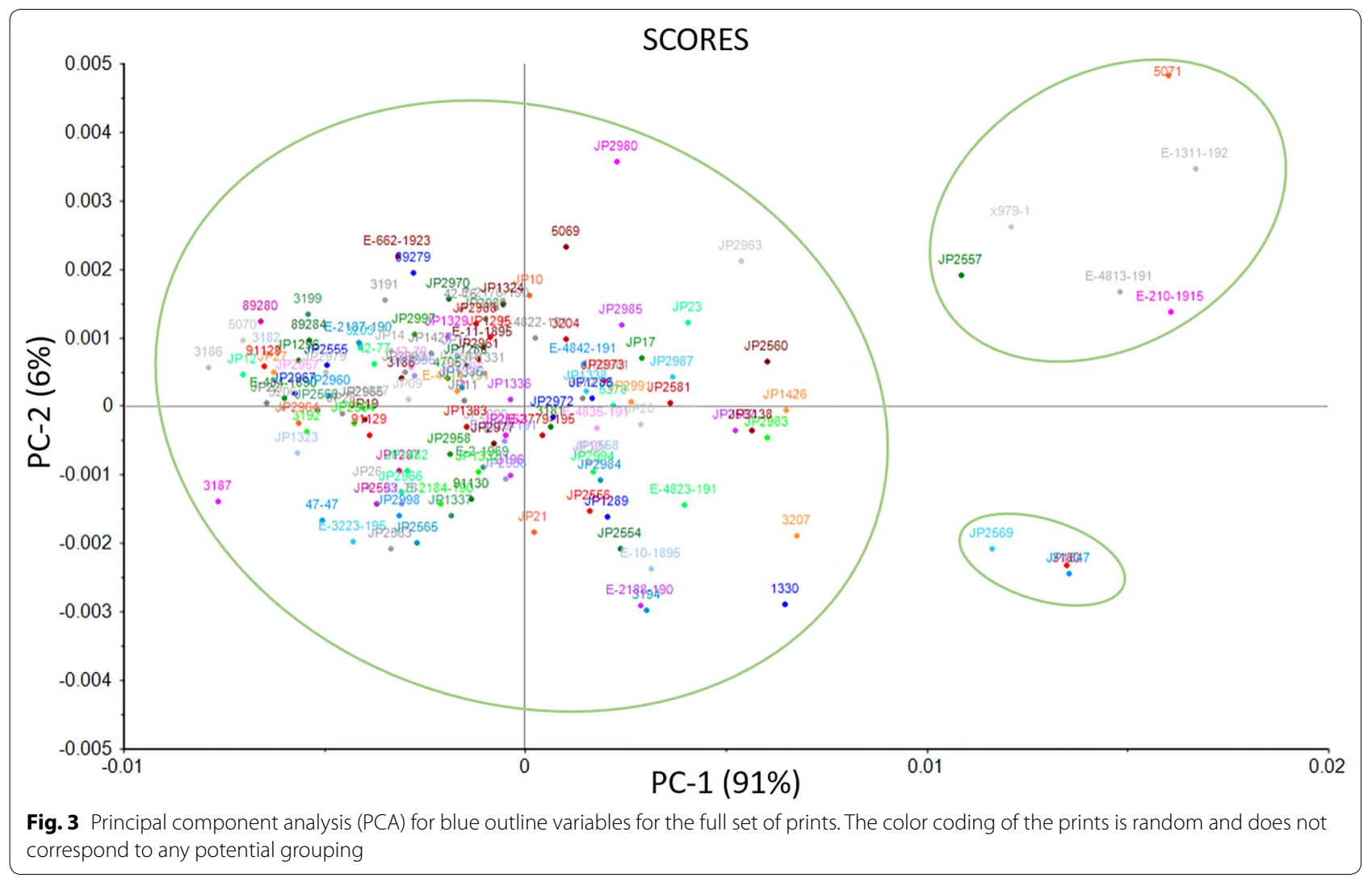




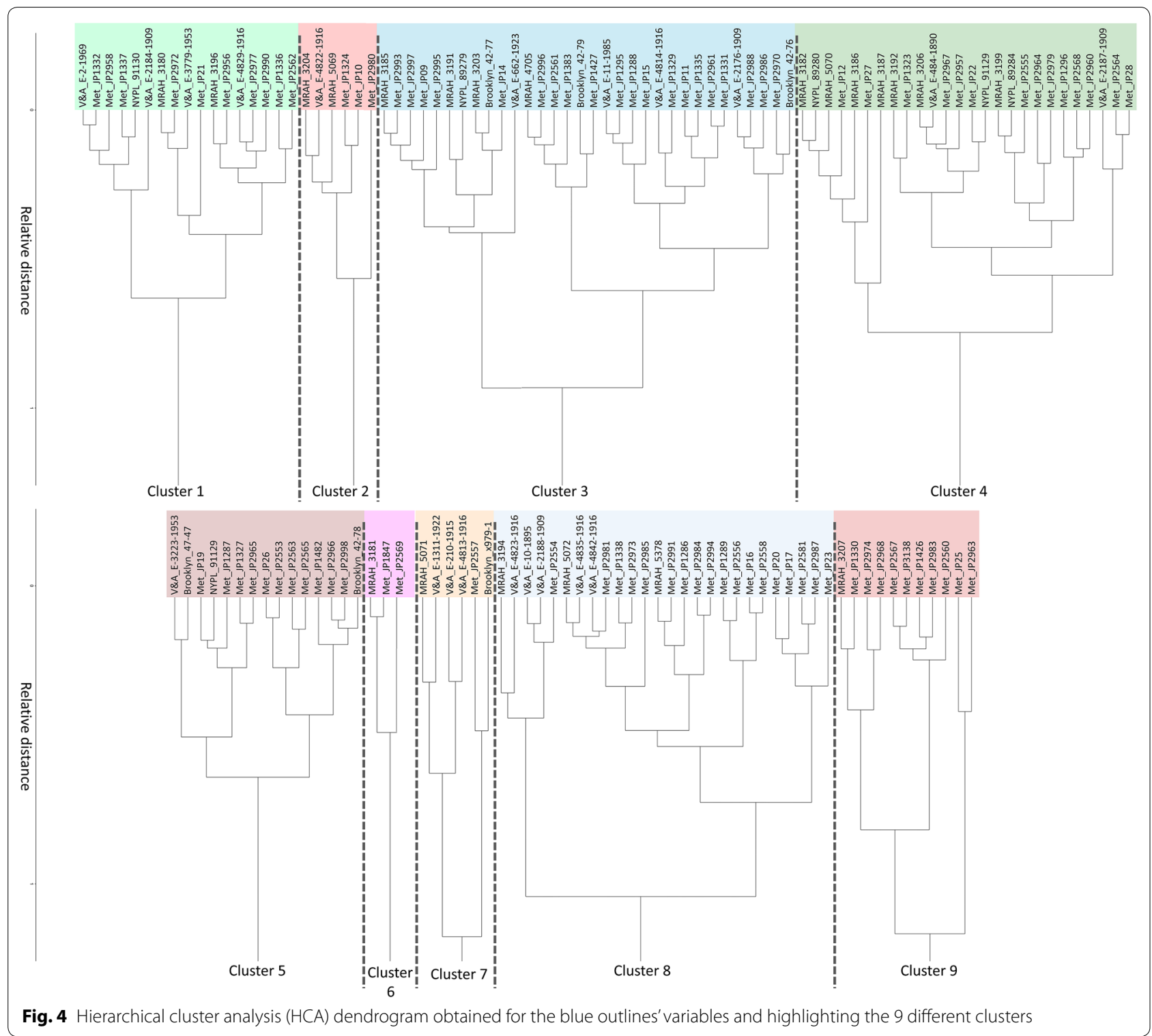

Prussian blue and indigo used for the outlines. To test the hypothesis, pigments and colorants found in impressions of the same print belonging to different clusters were compared. As an example, a UV-induced fluorescent yellow colorant was used in JP2957 and JP2555, both in cluster 4, while JP1330, a print from the same design found in cluster 9, features a non-fluorescing yellow for the same details (Fig. 6). This seems to indicate that the computer-aided clustering is accurate. Nonetheless, this confirmation was extended further.

Similar observations were made for the use of safflower red along with vermilion in the lightning bolt in JP2961 and JP11, both in cluster 3 , while only vermilion was used in the lightning bolt for JP2567, which is found in cluster
9. Vermilion was also used alone for the red areas of the kimono in JP1330 in cluster 9, similarly to JP2567. Apart from the red and yellow organic colorants, arsenic sulfide pigments, namely natural orpiment and amorphous (or semi amorphous) arsenic sulfide were also used to verify the validity of the different clusters. From these analyses, it appears that no variations were observed between prints within a single cluster, proving the validity of the clustering.

When looking at the actual reflectance spectrum of the outlines, it is interesting to note that all prints found in cluster 6 correspond to the spectral signal of the two best Met impressions of the Great Wave. These prints are characterized by impeccable line quality and minimal or 


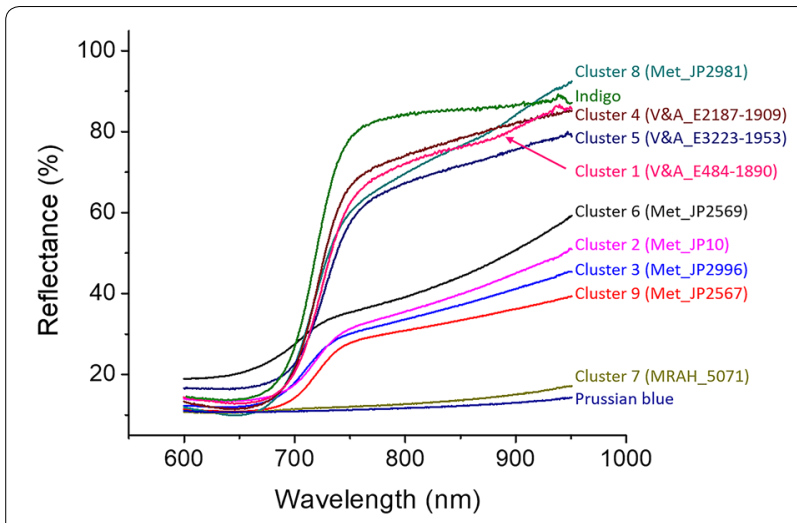

Fig. 5 Representative FORS spectra for selected prints belonging to each of the 9 clusters obtained using HCA. Reference spectra for pure Prussian blue and pure indigo are given for comparison purposes

no wear in the key-block printed areas and are indicative of an early production process. In fact, these two prints are widely considered to be among the earliest impressions of the Great Wave. In contrast, cluster 7 includes prints for which the outline appears to be composed only of Prussian blue. These prints are considered early twentieth century reproductions and were not created during the original production period of 1830-1832. Significant variations in the composition, including the intensity of the pink sky as well as the execution of the carved lines of the breaking wave, also indicate that these prints were created from newly carved blocks. These observations are part of the connoisseurship approach, which was applied to sort out the chronology of the various clusters created through multivariate analysis of the FORS data.

Once the clustering proved valid, the connoisseurship approach was applied to a selection of impressions in order to determine the relative order of the production process and to compare the various clusters. This was previously applied to the three impressions of Mishima Pass in Kai Province from the Met collection (JP2556, JP2970 and JP18), leading to the conclusion that JP2556 was created prior to JP2970 and JP18, the latter having been created later, along the additional 10 views ordered around 1835 [9]. This allowed for the conclusion that cluster 3 was printed later than cluster 8. A similar approach was applied to other impressions in the Met collection.

As suggested by Fig. 7, close observations of the impressions of Enoshima in Sagami Province (JP22 and JP2977) show that JP22 (cluster 4) presents less wear to the key-block than JP2977 (cluster 1), indicating that cluster 4 was realized prior to cluster 1 . A similar procedure was applied to other prints series from the Met collection. Consequently, based on the impressions of Honganji at Asakusa in Edo (JP1323 and JP2996), cluster 4 was created before cluster 3; cluster 9 was created before cluster 5 based on the impressions of In the Mountains of Tötomi Province (JP25 and JP2966); cluster 5 was created before cluster 4 based on the impressions of Lake Suwa in Shinano Province (JP2564 and JP2965); cluster 9 was created before cluster 4 according to the impressions of Morning after the Snow at Koishikawa in Edo (JP1330, JP2550 and P2957); cluster 9 was created before cluster 3 based on the impressions of Storm below Mount Fuji (JP11, JP2567 and JP2961); cluster 5 was created before cluster 3 according to the impressions of Surugadai in Edo (JP1287 and JP2995); cluster 8 was created before cluster 2 according to the impressions of Lake at Hakone in Sagami Province (JP17 and JP2980); cluster 5 before cluster 1 , itself before cluster 8 based on the observations of Tsukudajima in Musashi Province (JP23-8, JP265, JP2563-5 and JP2990-1); cluster 5 was created before cluster 4 according to the impressions of Ushibori in Hitachi Province (JP27-4, JP2565-5 and JP2964-4); and

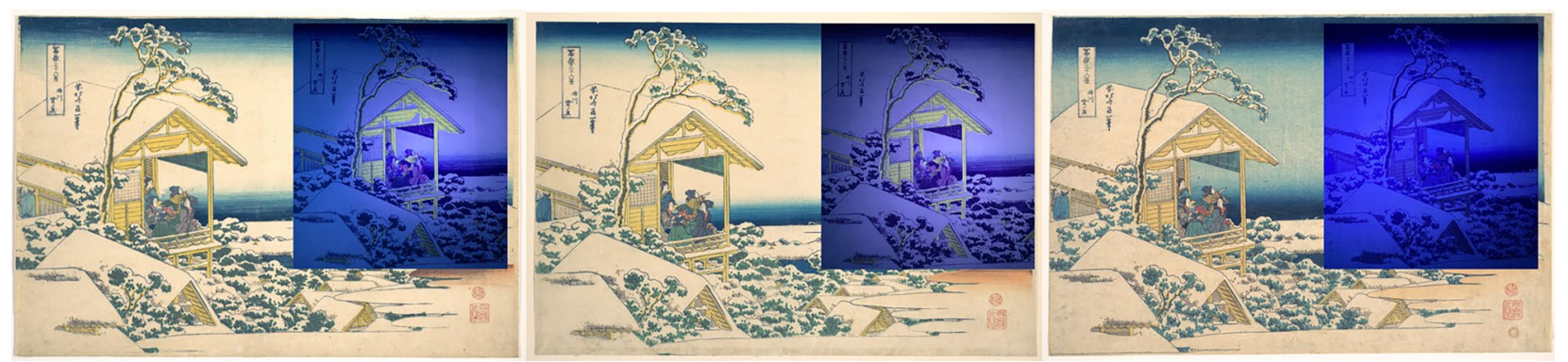

Fig. 6 Visible images and UV-induced visible luminescence (inserts) of the three impressions of Morning after the Snow at Koishikawa in Edo from the Met collection showing the use of fluorescing and non-fluorescing yellow colorants in prints belonging to different clusters. (left) JP2957, (middle) JP2555 and (right) JP1330. UV-induced visible luminescence images were acquired using a hand-help UV lamp and a digital camera and were not part of a thorough multispectral imaging examination. They were intended as an exploratory phase aimed at localizing organic colorants used in the various prints. As a result, they are not color calibrated using standard protocols 


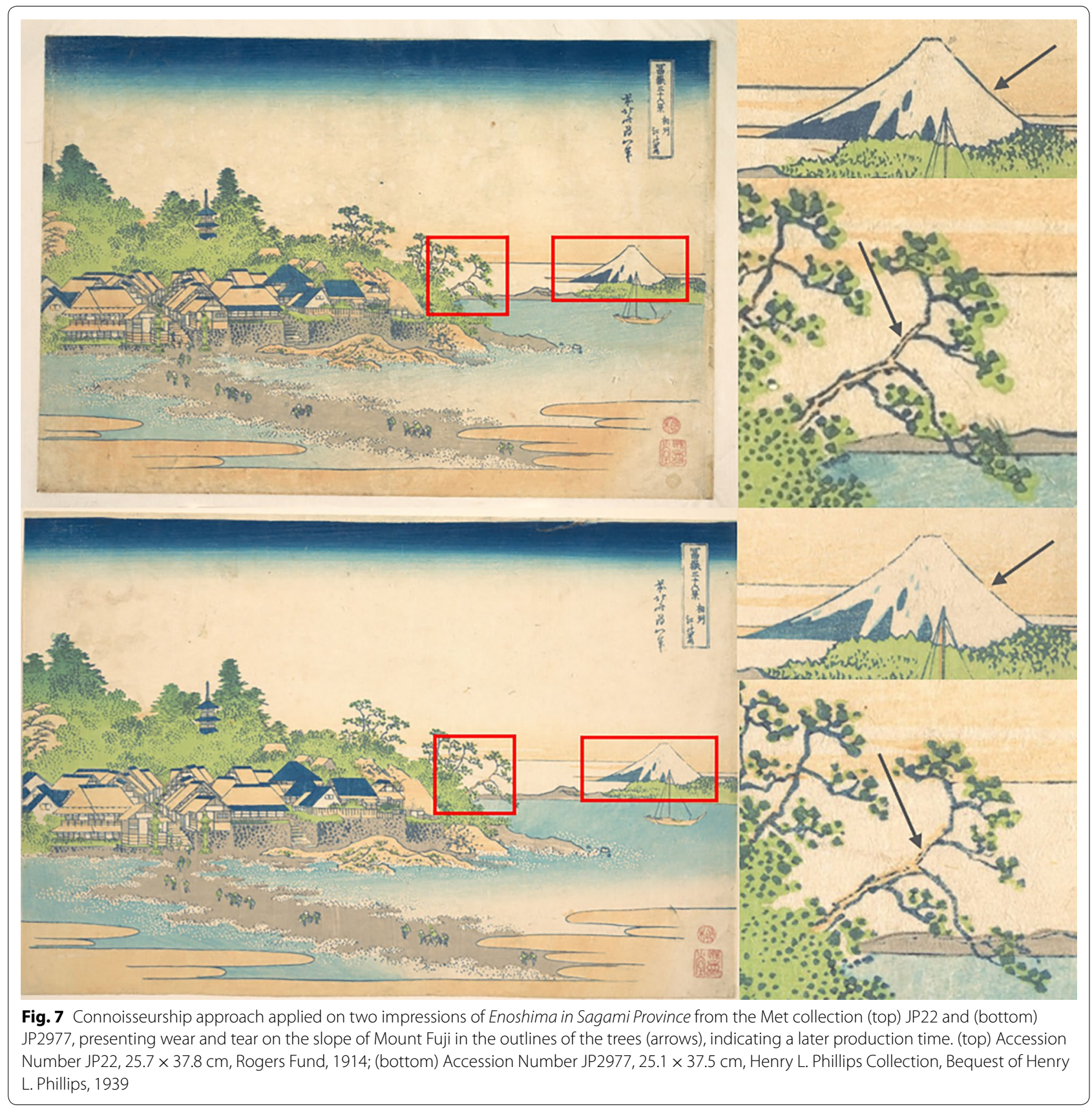

cluster 6 preceding all cluster based on the impressions of Under the Wave off Kanagawa (JP10, JP2569 and JP2972).

These various observations allow for a chronological order of production of the various clusters as follows, from earliest to latest: cluster 6 , cluster 9 , cluster 5 , cluster 4 , cluster 1 , cluster 8 , cluster 2 and cluster 7 , this last cluster containing prints identified as being earlytwentieth century reprints from historic or newly carved blocks. Cluster 3 is difficult to place in the chronology due to the lack of multiple comparisons. It appears to have been created after cluster 4 (and therefore, also clusters 6, 9 and 5) but it is difficult to know if it has been created before or after clusters 1,8 and 2. However, pure Prussian blue outlines as observed in cluster 7 are a significant indication of early twentieth-century reprints. Therefore, the Prussian blue/indigo nature of the outlines in cluster 3 represents a clear indication that the cluster has been created prior to cluster 7 . The final order of the print production process for the various clustersexcluding cluster 3 -is given in Fig. 8. 


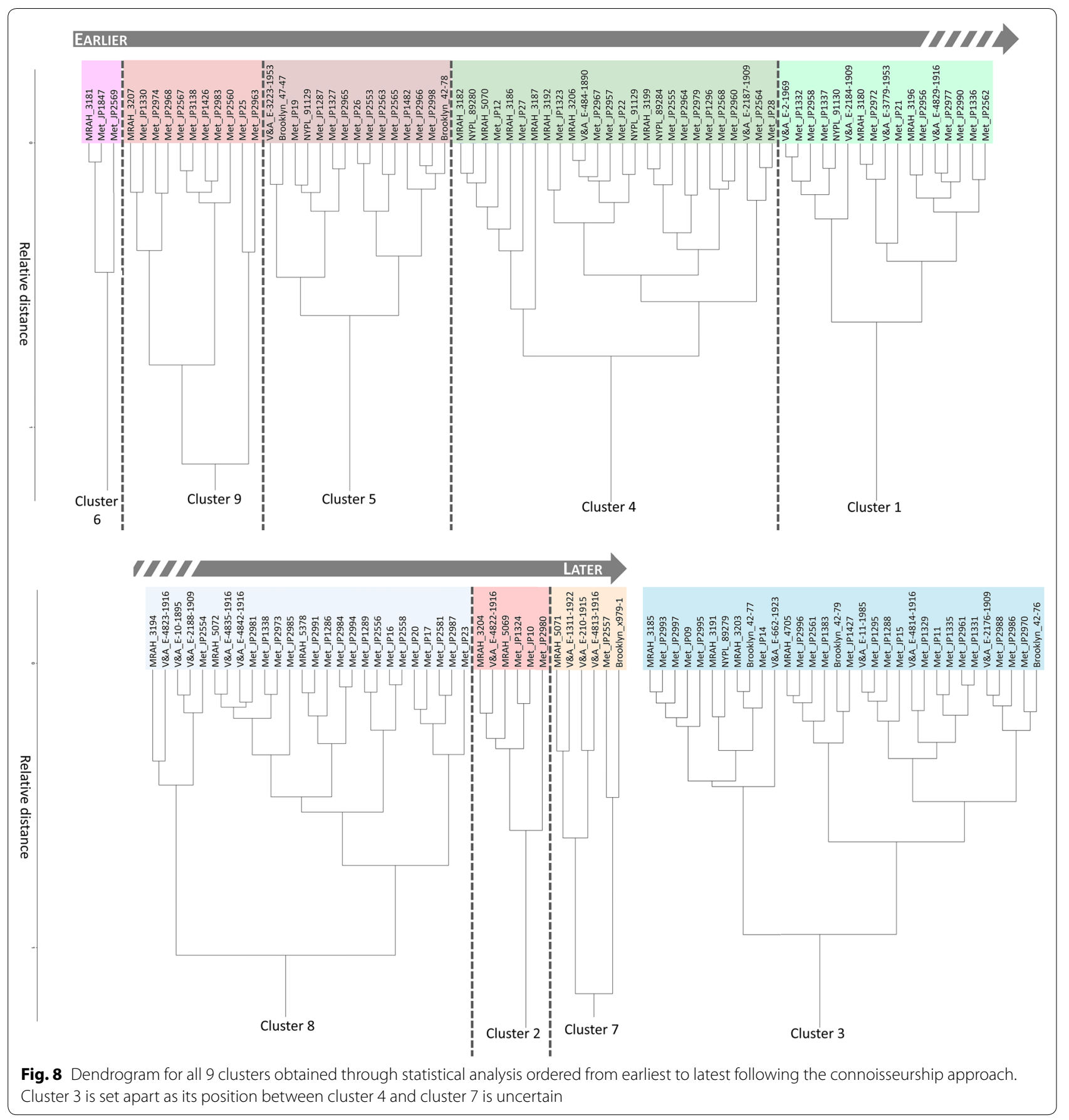

While not included in the statistical model, the FORS signal obtained from blue outlines in superb impressions of the Great Wave held by several other institutions corresponds almost perfectly to the Metropolitan Museum finest impressions of the same print. This would suggest that these additional impressions belong to a cluster of early works highlighted by the statistical study. While it appears easy to add impressions to the two extreme clusters (cluster 6, the early impressions of the Great Waves and cluster 7, the late nineteenth/ early twentieth century reproduction using only Prussian blue in the outlines), the statistical study could be expanded and therefore refined using an identical FORS instrument as the wavelength spacing is key to undertake the statistical treatment. 


\section{Conclusion}

The multivariate analysis applied to the blue outlines of the 141 Hokusai prints from the series Thirty-Six Views of Mount Fuji made it possible to differentiate various groups of prints within the print series, possibly corresponding to discrete printing sessions or batches. Two groups in particular can be easily distinguished from the rest. One group, cluster 6, corresponds to prints which exhibit great line quality and a lack-or small amount of-wear and tear on the key-block. All these features indicate an early production of the prints, possibly under the supervision of Hokusai himself.

The second group, cluster 7 corresponds to prints for which the outlines were created using only Prussian blue. Previous studies have dated these impressions to the late $-19^{\text {th }} /$ early $20^{\text {th }}$ century, decades after the production of the original impressions. Anomalies in the designs and composition indicate these impressions were created from re-carved blocks. The statistical approach differentiates not only these two extreme clusters but also several other groups of prints featuring outlines made with slightly different mixtures of indigo/Prussian blue. Upon data treatment, these prints were ultimately subdivided into an additional seven clusters, all characterized by their subtle variations in the Prussian blue/indigo mixtures. By applying the connoisseurship approach, assessing the overall quality of the prints, all nine clusters were ranked in a possible chronological order as follows: $6,9,5,4,1$, $8,2,7$. While the chronological order of most clusters can be confirmed by looking at various designs, cluster 3 lacked several comparison possibilities. Therefore, it was only possible to place it in the later clusters, being created after cluster 4 (and therefore 6, 9 and 5). This study also shows the applicability of multivariate analysis to such an important corpus of artworks, and how statistical methods can be applied to reach a better understanding of cultural heritage. Our conclusions are primarily limited to the corpus of prints examined. The study is obviously limited as we did not study the totality of printed impressions nor the totality of extant prints. Nonetheless, by including in our research prints from different collections, we hope to extend the applicability of our study and the reach of our conclusions. Indeed, by looking at different collections created from various donations and purchases over time, we ensure that the dataset is more representative of the production periods for the Thirty-Six Views. While the results of our study are valid in full only for the prints actually included in the dataset, the methodology could be easily extended to a great number of prints from other collections, allowing us to finally build a complete chronology of printing of this remarkable print series.

\section{Supplementary information}

Supplementary information accompanies this paper at https://doi. org/10.1186/s40494-020-00406-y.

Additional file 1. Additional figures and table.

\section{Abbreviations}

FORS: Fiber optic reflectance spectroscopy; SERS: Surface-enhanced Raman spectroscopy; PCA: Principal component analysis; HCA: Hierarchical cluster analysis; NIPALS: Non-linear iterative partial least squares.

\section{Acknowledgements}

This research is made possible with the financial support of the Andrew W. Mellon Foundation postdoctoral fellowship. We gratefully acknowledge John T. Carpenter, Mary Griggs Burke Curator of Japanese Art at The Metropolitan Museum of Art for his support and advices.

\section{Authors' contributions}

$M V$ and ML designed the research; MV and JW performed FORS analyses; MV and LB performed Raman analyses; MV wrote the manuscript; ML, LB, NV and ED reviewed the manuscript. All authors read and approved the final manuscript.

\section{Funding}

Not applicable.

\section{Availability of data and materials}

All data generated or analyzed during this study are included in this published article and in its additional file.

\section{Competing interests}

The authors declare that they have no competing interests.

\section{Author details}

${ }^{1}$ Department of Scientific Research, The Metropolitan Museum of Art, New York, NY 10028, USA. ${ }^{2}$ Science Section, Conservation Department, Victoria and Albert Museum, Cromwell Road, London SW7 2RL, UK. ${ }^{3}$ East Asian Collections Curatorial Department, Royal Museum of Art and History, Parc du Cinquantenaire 10, 1000 Brussels, Belgium. ${ }^{4}$ Conservation Department, The Brooklyn Museum, Brooklyn, NY 11238, USA. ${ }^{5}$ Prints and the Spencer Collection, The New York Public Library, New York City, NY 10018, USA. ${ }^{6}$ Present Address: Northwestern University/Art Institute of Chicago Center for Scientific Studies in the Arts, Technological Institute, 2145 Sheridan Road, Evanston, IL 60208, USA.

Received: 24 April 2020 Accepted: 16 June 2020

Published online: 26 June 2020

\section{References}

1. Meech-Pekarik J. The world of the Meiji print: impressions of a new civilization. 1st ed. New York: Weatherhill; 1986

2. Kanada MM. Color woodblock printmaking: the traditional method of Ukiyo-e. Tokyo: Shufunotomo; 2000.

3. Salter R. Japanese woodblock printing. London: A. \& C. Black; 2001.

4. FitzHugh EW. Prussian blue. In: FitzHugh EW, editor. Artists' pigments: a handbook of their history and characteristics, vol. 3. Washington: National Gallery of Art; 1997. p. 191-217.

5. Bailey K. A note on Prussian blue in nineteenth-century Canton. Stud Conserv. 2012;57:116-21. https://doi.org/10.1179/2047058412Y.00000 00002.

6. Bailey K. Personal communication 2020

7. Smith HD. Hokusai and the Blue Revolution in Edo Prints. In: Carpenter JT, editor. Hokusai and his age: ukiyo-e painting, printmaking and book illustration in late Edo Japan. Amsterdam: Hotei; 2005. p. 234-69.

8. Derrick M, Newman R, Wright J. Characterization of yellow and red natural organic colorants on japanese woodblock prints by EEM fluorescence 
spectroscopy. J Am Inst Conserv. 2017. https://doi.org/10.1080/01971 360.2016.1275438.

9. Vermeulen M, Leona M. Evidence of early amorphous arsenic sulfide production and use in Edo period Japanese woodblock prints by Hokusai and Kunisada. Herit Sci. 2019;7:73. https://doi.org/10.1186/s4049 4-019-0318-2.

10. Korenberg C, Pereira Pardo L, McElhinney PJ, Dyer J. Developing a systematic approach to determine the sequence of impressions of Japanese woodblock prints: the case of Hokusai's 'Red Fuji'. Herit Sci. 2019;7:1-11. https://doi.org/10.1186/s40494-019-0250-5.

11. Vermeulen M, Müller EMK, Leona M. Non-invasive study of the evolution of pigments and colourants use in 19th century Ukiyo-e. Arts Asia. 2020;50:103-14.

12. Biron C, Mounier A, Le Bourdon G, Servant L, Chapoulie R, Daniel F. A blue can conceal another! Noninvasive multispectroscopic analyses of mixtures of indigo and Prussian blue. Color Res Appl. 2019. https://doi. org/10.1002/col.22467.

13. Self J, Hirose N. Japanese art signatures: a handbook and practical guide. Rutland: C.E. Tuttle Co; 1987.

14. Marks A. Publishers of Japanese woodblock prints: a compendium. Leiden, Boston: Hotei Publishing; 2011.

15. Keyes R, Morse P. Catalogue Raisonné of the single-sheet colour woodblock prints of Katsushika Hokusai (1760-1849). Hokusai Prints Catalogue Raisonne 2017. https://www.dh-jac.net/db1/booksrske/search.php.

16. Moretti G, Gervais C. Raman spectroscopy of the photosensitive pigment Prussian blue. J Raman Spectrosc. 2018;49:1198-204. https://doi. org/10.1002/jrs.5366.

17. Bell IM, Clark RJH, Gibbs PJ. Raman spectroscopic library of natural and synthetic pigments (pre- $\approx 1850$ AD). Spectrochim Acta Part A Mol Biomol Spectrosc. 1997;53:2159-79. https://doi.org/10.1016/S1386 -1425(97)00140-6.

18. Burgio L, Clark RJH. Library of FT-Raman spectra of pigments, minerals, pigment media and varnishes, and supplement to existing library of Raman spectra of pigments with visible excitation. Spectrochim Acta Part A Mol Biomol Spectrosc. 2001;57:1491-521. https://doi.org/10.1016/ S1386-1425(00)00495-9.

19. Leona M. Microanalysis of organic pigments and glazes in polychrome works of art by surface-enhanced resonance Raman scattering. Proc Natl Acad Sci. 2009;106:14757-62. https://doi.org/10.1073/pnas.0906995106.

20. Camo Software AS. The Unscrambler Appendices: Method References. 2013. PDF from CAMO website. http://camo.com/downloads/U9.6pdfm anual/TheUnscramblerMethodReferences.pdf

21. Camo Software AS. The unscrambler methods. 2013. PDF from CAMO website. https://www.camo.com/downloads/U9.6pdfmanual/TheUn scramblerMethods.pdf.
22. Gettens RJ, Stout GL. Painting materials: a short encyclopaedia. unabridged and corr. republ. New York, Van Nostrand, 1942, Neuaufl. New York, NY: Dover; 1966.

23. Indigo-CAMEO. CAMEO 2019. http://cameo.mfa.org/wiki/Indigo.

24. Prussian blue_CAMEO. CAMEO 2019. http://cameo.mfa.org/wiki/Pruss ian_blue.

25. Vermeulen M, Janssens K, Sanyova J, Rahemi V, McGlinchey C, De Wael $K$. Assessing the stability of arsenic sulfide pigments and influence of the binding media on their degradation by means of spectroscopic and electrochemical techniques. Microchem J. 2018;138:82-91. https://doi. org/10.1016/j.microc.2018.01.004.

26. Vermeulen M, Nuyts G, Sanyova J, Vila A, Buti D, Suuronen J-P, et al. Visualization of $\mathrm{As}(\mathrm{III})$ and $\mathrm{As}(\mathrm{V})$ distributions in degraded paint microsamples from Baroque- and Rococo-era paintings. J Anal At Spectrom. 2016;31:1913-21. https://doi.org/10.1039/c6ja00134c.

27. Vermeulen M, Sanyova J, Janssens K, Nuyts G, De Meyer S, De Wael K. The darkening of copper- or lead-based pigments explained by a structural modification of natural orpiment: a spectroscopic and electrochemical study. J Anal At Spectrom. 2017;32:1331-41. https://doi.org/10.1039/ C7JA00047B.

28. Berbers SVJ, Tamburini D, van Bommel MR, Dyer J. Historical formulations of lake pigments and dyes derived from lac: a study of compositional variability. Dyes Pigm. 2019;170:107579. https://doi.org/10.1016/j.dyepi g.2019.107579.

29. Albrecht M, de Noord O, Meloni S, van Loon A, Haswell R. Jan Steen's ground layers analysed with Principal Component Analysis. Herit Sci. 2019:7:53. https://doi.org/10.1186/s40494-019-0295-5.

30. Nabais P, Melo MJ, Lopes JA, Vitorino T, Neves A, Castro R. Microspectrofluorimetry and chemometrics for the identification of medieval lake pigments. Herit Sci. 2018;6:13. https://doi.org/10.1186/s40494-018-0178-1.

31. van Driel BA, van den Berg KJ, Gerretzen J, Dik J. The white of the 20th century: an explorative survey into Dutch modern art collections. Herit Sci. 2018;6:16. https://doi.org/10.1186/s40494-018-0183-4.

32. Jolliffe IT, Cadima J. Principal component analysis: a review and recent developments. Phil Trans R Soc A. 2016;374:20150202. https://doi. org/10.1098/rsta.2015.0202.

\section{Publisher's Note}

Springer Nature remains neutral with regard to jurisdictional claims in published maps and institutional affiliations.

\section{Submit your manuscript to a SpringerOpen ${ }^{\circ}$ journal and benefit from:}

- Convenient online submission

- Rigorous peer review

- Open access: articles freely available online

- High visibility within the field

- Retaining the copyright to your article

Submit your next manuscript at $\boldsymbol{\nabla}$ springeropen.com 